\title{
Hormonal response during a fenfluramine-associated panic attack
}

A.H.G. Vieira ${ }^{2}$,

R.T. Ramos ${ }^{2}$ and V. Gentil ${ }^{1}$
1Departamento de Psiquiatria LIM-23, Faculdade de Medicina, Universidade de São Paulo, 01065-970 São Paulo, SP, Brasil

${ }^{2}$ Instituto de Psiquiatria, Hospital das Clínicas, Faculdade de Medicina, Universidade de São Paulo, 05403-010 São Paulo, SP, Brasil

\author{
Correspondence \\ A.H.G. Vieira \\ Departamento de Psiquiatria LIM-23 \\ Faculdade de Medicina, USP \\ Caixa Postal 8091 \\ 01065-970 São Paulo, SP \\ Brasil \\ Fax: 55 (011) 853-5032 \\ E-mail: ahgvfilh@usp.br
}

Publication supported by FAPESP

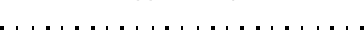

Received March 29, 1996

Accepted March 10, 1997

\begin{abstract}
Secretion curves for prolactin, cortisol, TSH, and GH from a 37-year old woman with dysthymia and panic disorder with agoraphobia were determined one day prior to (day I), and during a panic attack (day II) associated with an oral dose of $60 \mathrm{mg}$ dl-fenfluramine, a drug known to increase anticipatory anxiety. The increased cortisol secretion observed is discussed in relation to the hormonal correlates of anxiety and the possible role of depression, dl-fenfluramine, and serotonergic receptor sensitivity.
\end{abstract}

Key words

- Panic

- Fenfluramine

- Hormone secretion

- Serotonin

- Cortisol

Several lines of evidence implicate serotonin (5-HT) in the pathophysiology of panic disorder. Serotonergic antidepressants such as clomipramine $(1,2)$ and fluvoxamine (3) seem to be more potent in panic suppression than drugs acting mainly on noradrenergic neurotransmission such as imipramine and maprotiline. The occurrence of initial worsening in about $30 \%$ of panic patients treated with clomipramine (4) suggests that abnormalities in 5-HT receptor sensitivity may be the pathophysiologic condition underlying the serotonergic dysfunction in panic disorder $(5,6)$. Since serotonin is also involved in the releasing mechanisms of prolactin and cortisol, challenge secretion tests with these hormones have been systematically used to assess the 5-HT receptor status in panic disorder $(7,8)$.

Challenge tests with dl-fenfluramine (FEN), a phenylethylamine derivative that releases presynaptic 5-HT and inhibits 5-HT reuptake, are frequently used to assess the responsiveness of the serotonergic system in several psychiatric disorders such as depression (9), bulimia nervosa (10), obsessivecompulsive disorder (11), schizophrenia (12), and social phobia (11).

Targum and Marshall (7) administered $60 \mathrm{mg}$ FEN to 9 women with panic disorder, 9 with major depressive disorder, and 9 controls. Panic patients showed significantly greater anxiety response and prolactin and cortisol secretion compared to patients with major depression or control subjects. High anxiety levels were observed for several hours after FEN administration but the occurrence of panic attacks was not adequately described. Targum (8) suggests that FEN can induce a slow rising anxiety state that can persist for several hours contrasting with the acute panic attacks observed with lactate.

We report the acute hormonal changes that occurred during a well-documented panic 
attack triggered by a single dose of FEN in a patient with depressive and anxious symptoms.

A., a 37-year old female, had a 3.5 year history of depressive symptoms (Hamilton Depression Rating Scale, HDRS, total score $=26$ ), and several episodes of anxiety with autonomic symptoms weekly, meeting DSMIII-R criteria for dysthymia and panic disorder with agoraphobia. Physical, neurological, blood chemistry, cardiologic, and routine EEG evaluations were normal. Her sister committed suicide at the age of 33. A. was taking trimipramine (30 mg/day), bromazepan (6 mg/day), and thioridazine ( $25 \mathrm{mg} /$ day) for 2 weeks before the events described here, but was still presenting panic attacks and depressive symptoms at the time of admission.

After giving informed consent, A. was admitted to a psychiatric ward investigating neuroendocrine aspects of affective disorders. Medication was discontinued for 6 days, and a saline vs FEN test was performed on 2 days following an uneventful wash-out period of 6 days, where no panic attack was observed.

The fenfluramine stimulation test (FFT) was performed in the morning, with the patient resting in bed. The patient had had a light breakfast 90 min before the procedure, and was not allowed to sleep during the test. A butterfly needle was inserted into a forearm vein and kept patent with normal saline. Blood samples for determination of serum prolactin, GH, cortisol, and TSH levels were drawn at 9:00 a.m. (pre-drug levels), and hourly thereafter until 1:00 p.m. Serum was separated promptly by centrifugation and stored at $-20^{\circ} \mathrm{C}$ until assayed. A single oral dose of $60 \mathrm{mg}$ FEN (marketed as Ponderax ${ }^{\circledR}$, Itherapia Pharmavertrieb $\mathrm{GmbH}$, Munich, Germany; used for weight reduction in obesity) was administered immediately after the first blood sample was drawn. The same procedure had been performed one day before the FFT without FEN (saline condition). No oral placebo was administered. Since the patient was participating in a study of the neuroendocrine aspects of depression neither the research staff nor the patient were aware of the possible occurrence of a panic attack.

On day two, $2 \mathrm{~h}$ after dl-FEN intake, $\mathrm{A}$. reported a sudden fear of dying, derealization, paresthesia, sweating, faintness, tachycardia, and cold hands, reaching a peak within $3 \mathrm{~min}$. Her heart rate was $114 / \mathrm{min}$, and blood pressure 140/70. The full blown panic attack lasted about $10 \mathrm{~min}$, with decreasing symptoms over the next $90 \mathrm{~min}$, and residual complaints of tiredness and sadness. Figure 1 presents the hormone curves obtained after FEN and saline.

This well-defined panic attack contrasts with the long-lasting increases of anxiety levels described in FEN challenge tests. Targum (8) reported a greater cortisol response to FEN, but not to lactate, in panic patients than in normal controls suggesting that the fenfluramine-provoked anxiety in panic patients is more closely linked to anticipatory anxiety than to the panic attack itself. The panic attack and the hormonal changes observed did not seem to be due to nonspecific stress or anxiety associated with the experimental manipulation since no changes were found during the saline infusion or before the panic attack.

Fenfluramine is known to increase cortisol and prolactin, but the very abrupt rise and the magnitude of the cortisol changes observed $(+270 \mathrm{ng} / \mathrm{ml})$ are hardly explained by FEN alone. Indeed, Kasper et al. (9) gave FEN to 30 patients with major depression and none of them had a cortisol increase larger than $190 \mathrm{ng} / \mathrm{ml}$ (median response $=63$ $\mathrm{ng} / \mathrm{ml})$. Thus, a complex interaction between FEN and the mechanisms involved in the panic attacks and depression may have been responsible for our results.

The basal hormone levels and intensity of depressive symptoms on FEN day were similar to those of the patients of the Kasper study (HDRS $=27)$, suggesting that the pa- 

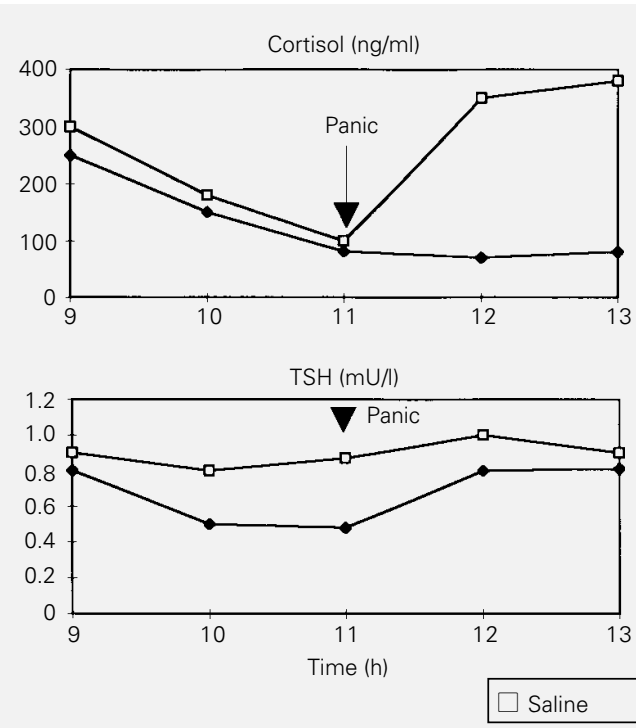

tient differed only in the antecedents of panic attacks. However, a direct causal role of FEN in triggering panic cannot be inferred from this case.

Klein (13) recently proposed that different provocative tests performed on panic patients may induce different types of anxiety response. Procedures such as lactate, bicarbonate, $5 \%$ carbon dioxide, and isoproterenol hydrochloride challenges would elicit a false alarm of suffocation, provoking a state close to the panic attacks with no activation of the hypothalamic-pituitary-adrenal (HPA) axis, while drugs such as yohimbine, caffeine, meta-chlorophenylpiperazine (mCPP), and FG 7142 (a benzodiazepineinverse agonist) would induce a state related to chronic fear and anticipatory anxiety with HPA activation.

Spontaneous panic attacks are rare in experimental settings and those experimentally induced by agents such as sodium lactate, yohimbine, and $\mathrm{mCPP}$ infusion may introduce confounding factors since hormone concentrations can vary even under subtle influences. Even hormonal measurements during patient exposure to agoraphobic situations may be influenced by exertion (14). Cameron et al. (15) found small to moderate rises in prolactin during panic attacks in 4 patients being withdrawn from treatment and who had panic attacks in a 24-h follow-up during which blood was sampled every $4 \mathrm{~h}$. These changes were significantly correlated with the severity of their previous panic symptoms. The GH levels were raised in only one case.

As far as we know, this is the first report on TSH levels during a panic attack. Since the destruction of the raphe system blocked the inhibitory effects of FEN on TSH secretion and serotonergic agonists such as Ltryptophan can produce a modest increase of serum GH in humans (16), changes in TSH and GH levels were expected, but no change was observed with time.

Although our results suggest HPA activation in a chronic depressive subject, the symptoms observed in our patient were clinically identical to a true panic attack and did not resemble a nonspecific long-lasting anxiety state. Considering the limitations of a single case report, our data suggest that fenfluramine can induce true panic attacks associated with HPA activation in depressive patients with a previous history of panic disorder. The magnitude of the hormonal increases may be compatible with the hypothesis of 5-HT receptor hypersensitivity in panic disorder.
Figure 1 - Serum hormone levels on the saline and fenfluramine days. 


\section{References}

1. Modigh K, Westberg P \& Ericksson E (1992). Superiority of clomipramine over imipramine in the treatment of panic disorder: a placebo-controlled trial. Journal of Clinical Psychopharmacology, 12: 251261.

2. Gentil V, Lotufo F, Andrade LH, Cordás TA, Bernik M, Ramos RT, Maciel L, Miyakawa E \& Gorenstein C (1993). Clomipramine, a better reference drug for panic/agoraphobia. Journal of Psychopharmacology, 7: 316-324.

3. Den Boer JA \& Westenberg HGM (1988). Effect of a serotonin and noradrenalin uptake inhibitor in panic disorder: a doubleblind comparative study with fluvoxamine and maprotiline. International Clinical Psychopharmacology, 3: 59-74.

4. Ramos RT, Gentil V \& Gorenstein C (1993). Clomipramine and the initial worsening in panic disorder: beyond the jitteriness syndrome. Journal of Psychopharmacology, 7: 265-269.

5. Gentil V (1986). Mecanismo de ação das drogas anti-pânico. Jornal Brasileiro de Psiquiatria, 35: 155-162.

6. Kahn RS, Asnis GM, Wetzler S \& Van Praag HM (1988). Neuroendocrine evidence for serotonin receptor hypersensitivity in panic disorder. Psychopharmacology, 96: 360-364.
7. Targum SD \& Marshall LE (1989). Fenfluramine provocation of anxiety in patients with panic disorder. Psychiatry Research, 28: 295-306.

8. Targum SD (1992). Cortisol response during different anxiogenic challenges in panic disorder patients. Psychoneuroendocrinology, 17: 453-458.

9. Kasper $S$, Vieira AHG, Schmidt R \& Richter $P$ (1990). Multiple hormone responses to stimulation with dl-fenfluramine in patients with major depression before and after antidepressive treatment. Pharmacopsychiatry, 23: 76-84.

10. Halmi KS (1995). Basic biological overview of eating disorders. In: Bloom FE \& Kupfer Dj (Editors), Psychopharmacology: the Fourth Generation of Progress. Raven Press, New York.

11. Price LH, Goddard AW, Barr LC \& Goodman WK (1995). Pharmacological challenges in anxiety disorders. In: Bloom FE \& Kupfer Dj (Editors), Psychopharmacology: the Fourth Generation of Progress. Raven Press, New York.
12. Roth BL \& Meltzer HY (1995). The role of serotonin in schizophrenia. In: Bloom FE \& Kupfer Dj (Editor), Psychopharmacology: the Fourth Generation of Progress. Raven Press, New York.

13. Klein DF (1993). False suffocation alarms, spontaneous panics, and related conditions. Archives of General Psychiatry, 50: 306-317.

14. Woods SW, Charney DS \& McPherson CA (1987). Situational panic attacks. Archives of General Psychiatry, 44: 365-375.

15. Cameron OG, Lee MA, Curtin GC \& McCann DS (1987). Endocrine and physiological changes during "spontaneous" panic attacks. Psychoneuroendocrinology, 12: 321-331.

16. Meltzer HY, Wiita B, Tricou BJ, Simonovic M, Fang V \& Manov G (1982). Effect of serotonin precursors and serotonin agonists on plasma hormone levels. In: Ho BT, Schoolar JC \& Usdin E (Editors), Serotonin in Biological Psychiatry. Raven Press, New York. 